\title{
Evaluation of electrical load estimation in Diyala governorate (Baaquba city) based on fuzzy inference system
}

\author{
Siraj Manhal Hameed ${ }^{1}$, Hayder Khaleel AL-Qaysi², Ali Sachit Kaittan ${ }^{3}$, Mohammed Hasan Ali ${ }^{4}$ \\ ${ }^{1}$ Department of Computer Engineering, University of Diyala, Iraq \\ ${ }^{2}$ Department of Electronic Engineering, College of Engineering, University of Diyala, Iraq \\ ${ }^{3,4}$ Department of Electrical Power and Machines Engineering, University of Diyala, Iraq
}

\begin{tabular}{l} 
Article Info \\
\hline Article history: \\
Received Mar 18, 2021 \\
Revised Mar 24, 2021 \\
Accepted Apr 11, 2021 \\
\hline
\end{tabular}

\section{Keywords:}

Fuzzy inference system

Load estimation

Membership functions

\begin{abstract}
The evaluation of electrical load estimation is requisitely of any electrical power system. This manner is needed for system obligation, economical distribution and maintenance time of electrical system. In this paper, we propose electrical load estimation method based on fuzzy inference system which gives accurate results for estimated loads in Iraq (Diyala governorateBaaquba city). And it can assist the electrical generation and distribution system that depends on important parameters (temperature, humidity and the speed of the wind). By considering the parameters temperature, humidity and the speed of the wind. These parameters are applied as inputs to the fuzzy logic control system to obtain the normalize estimated load as output by electing membership functions. It is exceptionally valuable to form a choice by taking into consideration these assessed readings that come to from the proposed FIS that displayed in this paper with precision of 0.969 from the real stack request.
\end{abstract}

This is an open access article under the CC BY-SA license.

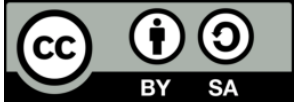

Corresponding Author:

Mohammed Hasan Ali

Department of Electrical Power and Machines Engineering

Diyala University

Diyala, Iraq

Email: moh80mmed@gmail.com

\section{INTRODUCTION}

Estimating the electrical load of power network is very necessary to planning the generation, transmission and distribution of any electrical power system, and it is very important process in designing and operating of any electrical energy management system at any country [1]. Any generating power scheduling needs information about load connected to the electric power generating plant [2]. The estimated load helps to avoid overloading, equipment failure occurrence, continuously evaluating the power system security and increasing the reliability of the power system [3]. There are many algorithms used to estimate electrical load, in this paper, Fuzzy logic is used to evaluate the electrical load estimation because it is a solution to complicated problems in all life fields, as it is similar to the human and making of decision [4], [5]. Fuzzy logic also replies doubts and mysterious points produced by language of human were everything cannot be labeled in accurate and separated expressions [6], [7]. Our fuzzy inference system (FIS) builds with three inputs relying upon the climate information, first input is a temperature, second input is a humiditypercentage and the third input is a wind-speed. All inputs have three triangular shapes membership functions to obtain the estimated electrical load with five triangular shapes membership functions and the output is normalized (in per unit) in order to be used at any size of load and at any time for the estimated of load. 


\section{FUZZY LOGIC SYSTEM}

Fuzzy logic is similar to the way human being interpret ideas. It has the possibility of collecting heuristics of human into computer-assisted making decision because it is multi-valued logic [7]-[11]. Fuzzy logic system suitable for additional tasks compared to classical form of logic. They were first flexibility for representation [12]-[14]. This quality is recognized by membership functions which give Fuzzy sets the capability of modeling in linguistic form. Fuzzy logic can be novel rout for realizing and making decision by considering imprecise information in which reality can have a value between 0 to 1 [15]-[19]. This process called as fuzziness: So, fuzziness comes from the uncertain and imprecise nature of concepts. Fuzzy logic deals with a form of thinking using specific mathematical formulas which supplies results based on a group of IF-THEN rules. It is best way to describing the behavior of systems which are unclear to be matching with specific mathematical analysis in difference to the traditional systems that cannot deal with inaccuracy or deficiency in information [20]-[25]. Fuzzy system is chiefly based on IF-THEN rules according to the following terms: Fuzzification, rule base, fuzzy inference, and fuzzification. A general fuzzy system is shown in Figure 1.

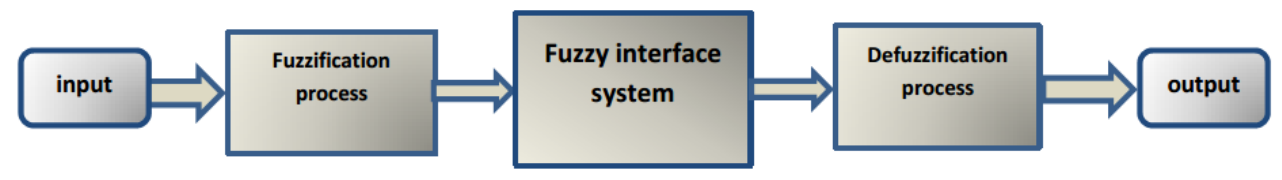

Figure 1. Fuzzy logic system

\section{PROPOSED METHOD}

The proposed fuzzy logic system that implemented to estimate the electrical load is described in Figure 2. The system is controlled by fuzzy logic system to decide the value of estimated load in Per Unit (minimum, small medium, medium, big medium and maximum) depending on the values of input parameters (temperature, humidity and wind speed).

The inputs of the proposed fuzzy logic system pass through the fuzzy inference system (FIS) as shown in Figure 3, to decide the estimated load by using rules in FIS in a way to obtain the best estimation. Table 1 described fuzzified input parameters of Iraq (Diyala governorate-Baaquba city) country which is considered in this study after applying Fuzzy inference system of type Mamdani. And the range of input parameters temperature, humidity and wind speed as shown in Table 1.

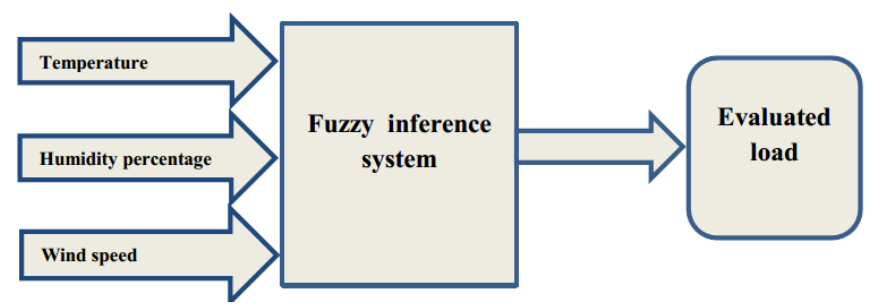

Figure 2. Proposed fuzzy logic system

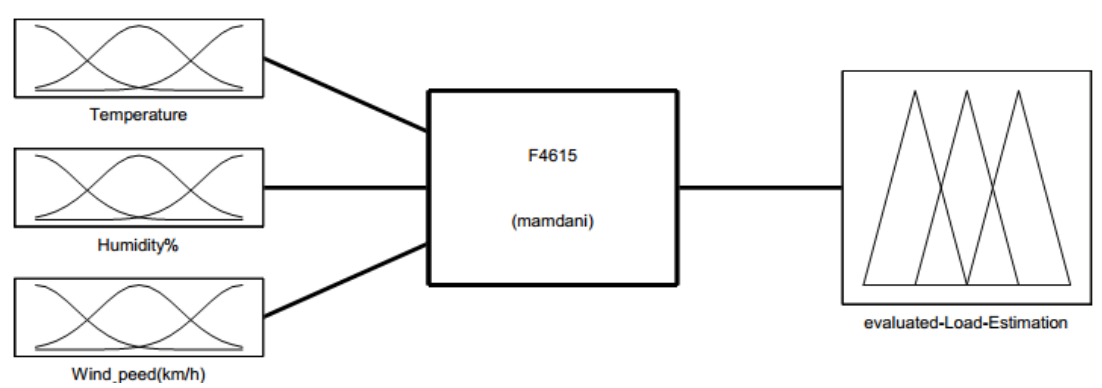

Figure 3. Fuzzy inference system 
Table 1. Input parameters and their ranges

\begin{tabular}{ccc}
\hline No. & Input parameter & Range \\
\hline 1 & Temperature & $0{ }^{0} \mathrm{C}$ to $33{ }^{0} \mathrm{C}$ \\
2 & Humidity percentage & $0 \%$ to $20 \%$ \\
3 & Wind speed & 0 to $40 \mathrm{~km} / \mathrm{h}$ \\
\hline
\end{tabular}

\section{RESULTS AND DISCUSSION}

The results of proposed fuzzy inference system with three input parameters and one evaluated output. This output represent the estimated load in (per unit system) of real power that in Mw and the base of per unit is $470 \mathrm{Mw}$ in Iraq (Diyala governorate-Baaquba city-western) for approximately one week from 29/12/2018 to 4/1/2019. The input parameters are shown in Figure 4 the temperature, Figure 5 the humidity and Figure 6 the wind speed and every one input has vertical axis with range from (0-1) represents the degree of membership functions. And the horizontal axis represents the range of every input parameter.

The range of temperature is from $\left(5^{\circ} \mathrm{C}\right)$ to $\left(17^{\circ} \mathrm{C}\right)$ and the range of humidity percentage is from $(50 \%)$ to $(60 \%)$ and the range of speed of the wind is from $(6 \mathrm{~km} / \mathrm{h})$ to $(28 \mathrm{~km} / \mathrm{h})$. Each one of the inputs have three trigonometric functions named minimum, medium and maximum. The minimum membership function is used for minimum input range values and medium membership function is used for medium input range values and maximum membership function is used for maximum input range values. The output have five trigonometric functions named minimum, small medium, medium, big medium and maximum as shown in Figure 7.

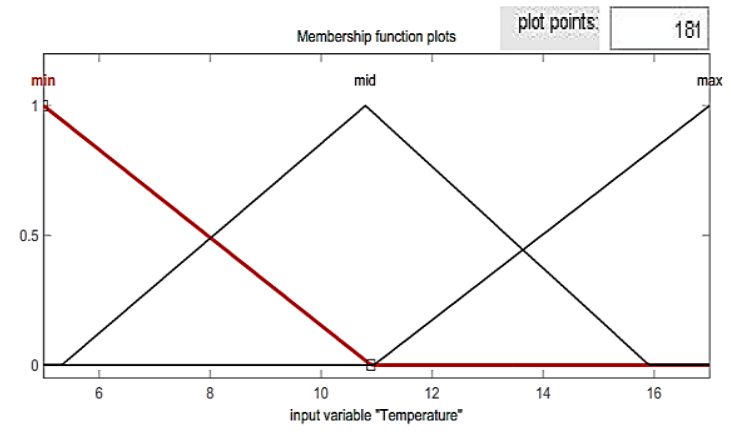

Figure 4. Membership functions of temperature

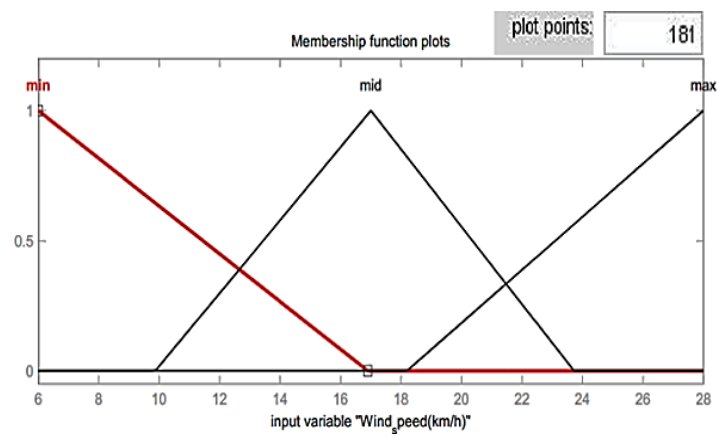

Figure 6. Membership functions of speed of the wind

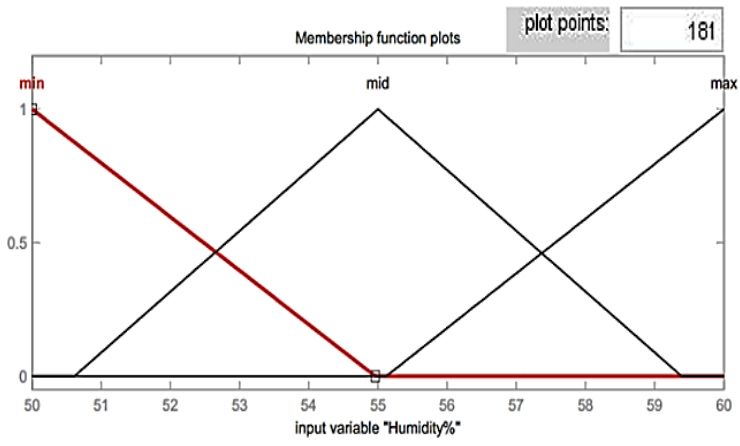

Figure 5. Membership functions of humidity percentage

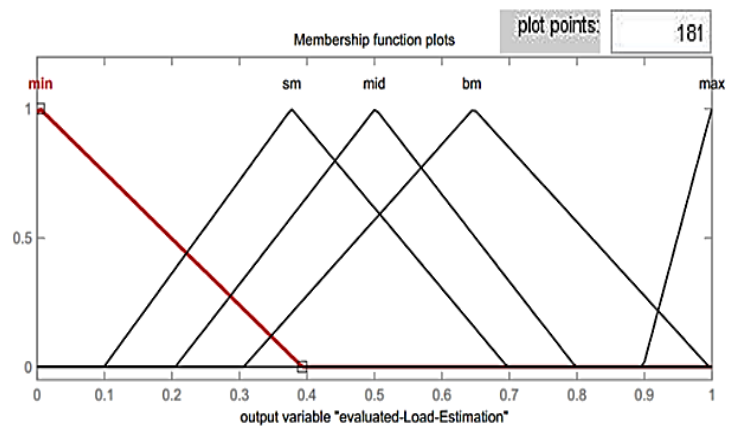

Figure 7. Membership functions of output (evaluated-load estimation)

The minimum and small medium represents the low power consumption in kilo watts (from $280 \mathrm{KW}$ to $330 \mathrm{KW})$ at the morning from ( 8 am to $12 \mathrm{am}$ ) because the residential load will decrease while the most people are in the work and their children at the school. And the maximum represent the highest power consumption (from $430 \mathrm{KW}$ to $470 \mathrm{KW}$ ) at the times ( $1 \mathrm{pm}$ to $4 \mathrm{pm}$ ) and (2 am to $7 \mathrm{am}$ ). And the rest of each day in the week the power consumption (from $331 \mathrm{KW}$ to $429 \mathrm{KW}$ ) between medium and big medium. The rules of fuzzy inference system (FIS) are shown in Figure 8. The three inputs with three membership functions gives 27 rules. The evaluation of electrical load estimation based on fuzzy inference system (FIS) is 
shown Figure 9 the rule viewer of fuzzy inference system FIS with three inputs (temperature, humidity percentage and the speed of the wind).

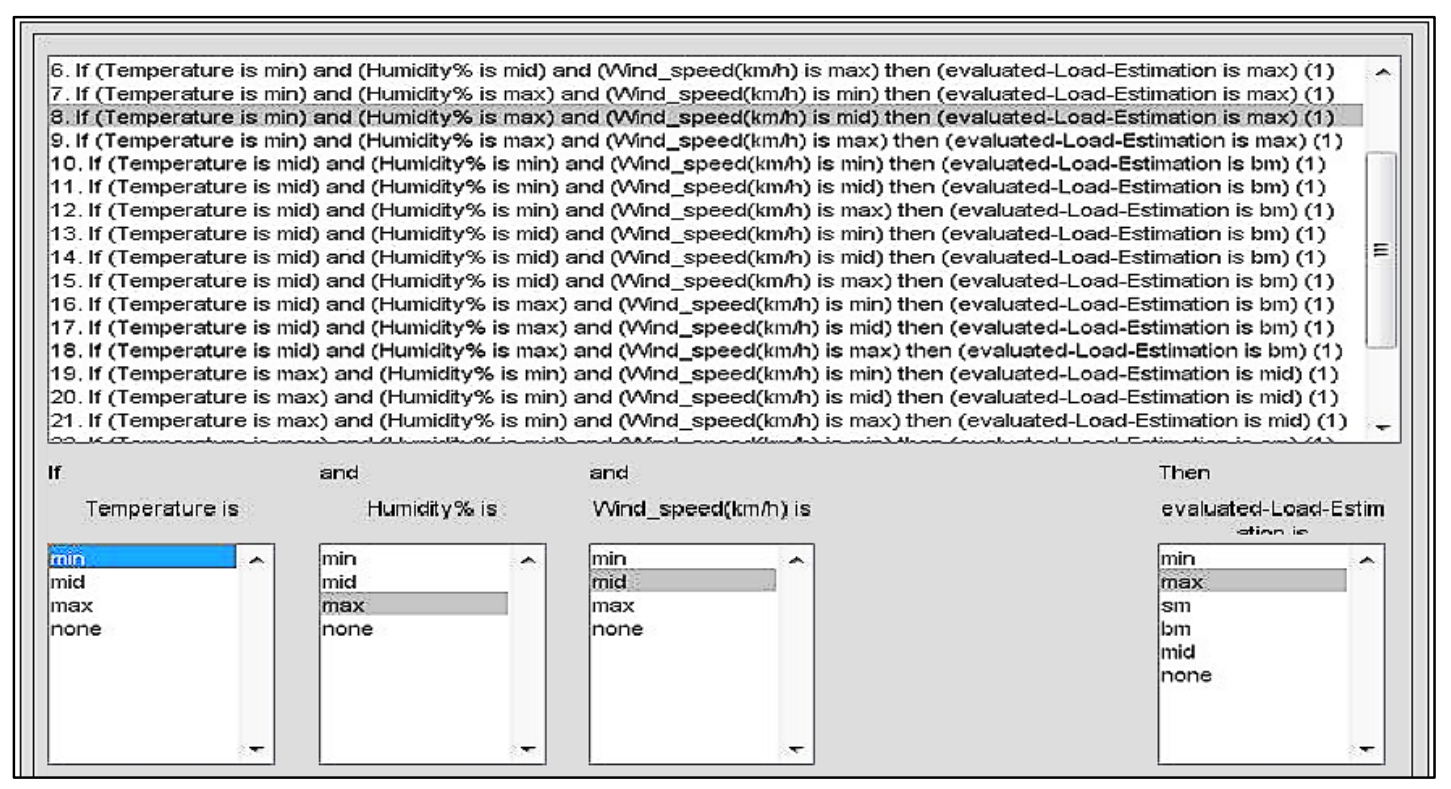

Figure 8. Rule of FIS
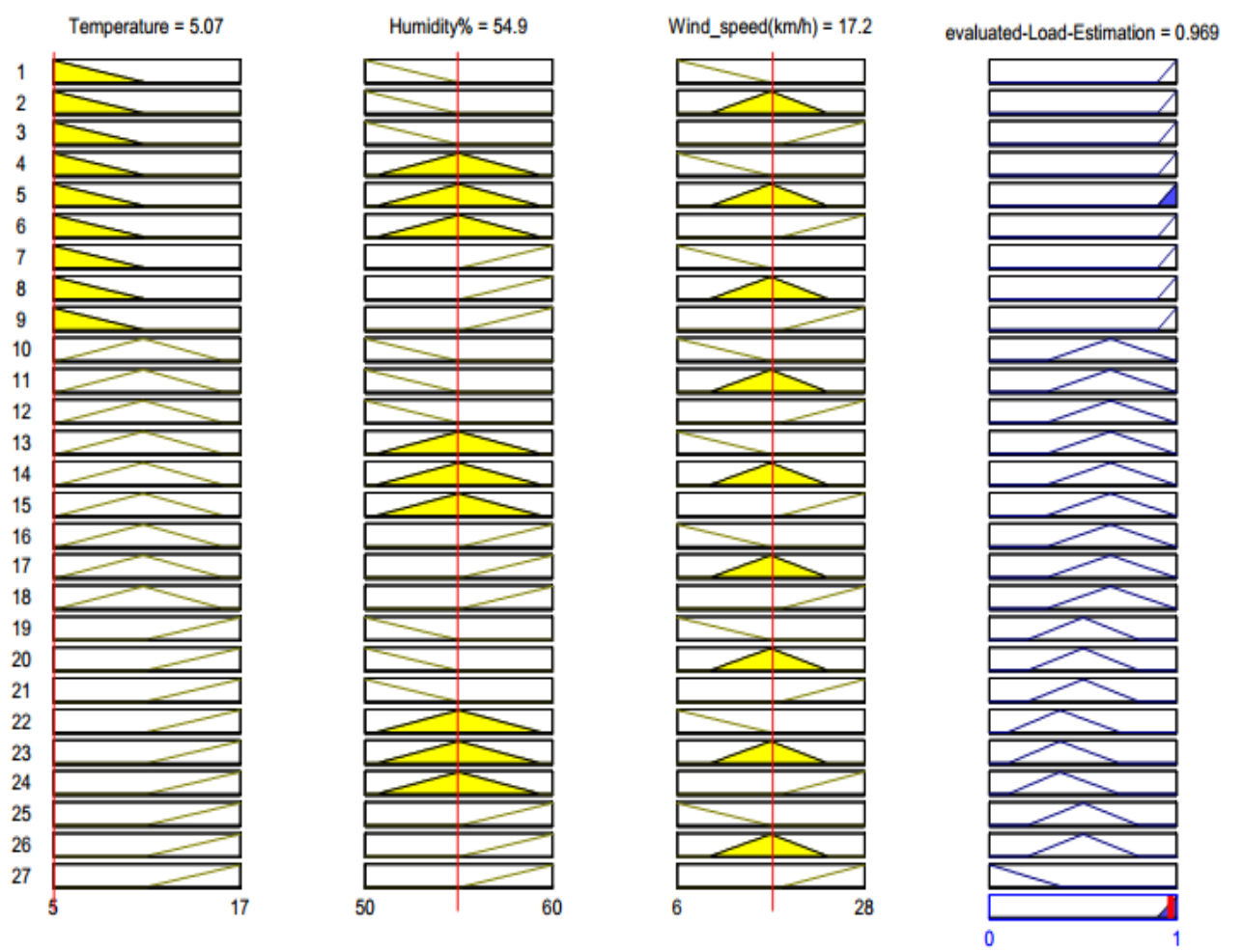

Figure 9. Rule viewer of FIS

The end of results shown in Table 2. The base of per unit system $470 \mathrm{KW}$ (470 KW represents the maximum load in western substation plant at Baaquba city-Diyala governorate-Iraq) for one day 31/12/2018 at the time interval from 29/12/2018 to 4/1/2019. 
Table 2. Real power consumption in kilo watts and the evaluation of electrical load estimation in one day

\begin{tabular}{|c|c|c|c|}
\hline Time (hour) & $\begin{array}{l}\text { Real power consumption in } \\
\text { kilo watts }\end{array}$ & $\begin{array}{l}\text { Real power consumption divided by } 470 \\
\text { KW in per unit system }\end{array}$ & $\begin{array}{l}\text { Electrical load estimation in } \\
\text { per unit system }\end{array}$ \\
\hline 8:00am & 340 & 0.723 & 0.700 \\
\hline 9:00am & 330 & 0.702 & 0.680 \\
\hline 10:00am & 317 & 0.674 & 0.653 \\
\hline 11:00am & 400 & 0.851 & 0.824 \\
\hline 12:00am & 400 & 0.851 & 0.824 \\
\hline $1: 00 \mathrm{pm}$ & 390 & 0.829 & 0.804 \\
\hline $2: 00 \mathrm{pm}$ & 341 & 0.725 & 0.703 \\
\hline 3:00pm & 343 & 0.729 & 0.707 \\
\hline $4: 00 \mathrm{pm}$ & 320 & 0.680 & 0.659 \\
\hline $5: 00 \mathrm{pm}$ & 320 & 0.680 & 0.659 \\
\hline $6: 00 \mathrm{pm}$ & 380 & 0.808 & 0.783 \\
\hline $7: 00 \mathrm{pm}$ & 450 & 0.957 & 0.927 \\
\hline $8: 00 \mathrm{pm}$ & 470 & 1 & 0.969 \\
\hline 9:00pm & 320 & 0.680 & 0.659 \\
\hline $10: 00 \mathrm{pm}$ & 350 & 0.744 & 0.721 \\
\hline $11: 00 \mathrm{pm}$ & 390 & 0.829 & 0.804 \\
\hline $12: 00 \mathrm{pm}$ & 417 & 0.887 & 0.859 \\
\hline 1:00am & 412 & 0.876 & 0.849 \\
\hline 2:00am & 380 & 0.808 & 0.783 \\
\hline 3:00am & 360 & 0.765 & 0.742 \\
\hline 4:00am & 330 & 0.702 & 0.680 \\
\hline 5:00am & 387 & 0.823 & 0.797 \\
\hline 6:00am & 418 & 0.889 & 0.861 \\
\hline 7:00am & 440 & 0.936 & 0.907 \\
\hline
\end{tabular}

\section{CONCLUSION}

The electrical stack estimation is outstandingly profitable to supervise the electrical control system. And three input parameters(temperature, humidity and the speed of the wind) are taken into thought to advancement the comes around and getting more precision in evaluating the comes almost that talking to control utilization in one day. It is especially important to create a choice by taking into thought these evaluated readings that come to from the proposed FIS that shown in this paper with accuracy of 0.969 from the genuine stack request. The results will be very helpful to making studies or analysis of electrical power system and designing a reliable distribution power system.

\section{REFERENCES}

[1] I. A. Ethmane, M. Maaroufi, A. K. Mahmoud, and A. Yahfdhou, "Optimization for Electric Power Load Forecast," International Journal of Electrical and Computer Engineering (IJECE), vol. 8, no. 5, pp. 3453-3462, 2018, doi: 10.11591/ijece.v8i5.pp3453-3462.

[2] I. Mukhlash, D. Yuanda, and M. Iqbal, "Mining Fuzzy Time Interval Periodic Patterns in Smart Home Data," International Journal of Electrical and Computer Engineering (IJECE), vol. 8, no. 5, pp. 3374-3385, 2018, doi: 10.11591/ijece.v8i5.pp3374-3385.

[3] W. N. W. Md Adnan, N. Y. Dahlan, and I. Musirin, "Modeling Baseline Energy Using Artificial Neural Network: A Small Dataset Approach," Indonesian Journal of Electrical Engineering and Computer Science (IJEECS), vol. 12, no. 2, pp. 662-669, 2018, doi: 10.11591/ijeecs.v12.i2.pp662-669.

[4] Y. I. Kudinov, V. A. Kolesnikov F. F. Pashchenko, A. F. Pashchenko, and L. Papic, "Optimization of fuzzy PID controller's parameters," Procedia Computer Science, vol. 103, pp. 618-622, 2017, doi: 10.1016/j.procs.2017.01.086.

[5] N. Ismail, I. Nursalim, H. M. Saputra, and T. S. Gunawan, "Implementation of Fuzzy Logic Control System on Rotary CarParking System Prototype," Indonesian Journal of Electrical Engineering and Computer Science (IJEECS), vol. 12, no. 2, pp. 706-715, 2018, doi: 10.11591/ijeecs.v12.i2.pp706-715.

[6] S. R. Salkuti, "Short-term optimal hydro-thermal scheduling using clustered adaptive teaching learning based optimization," International Journal of Electrical and Computer Engineering (IJECE), vol. 9, no. 5, pp. 3359-3365, 2019, doi: 10.11591/ijece.v9i5.pp3359-3365.

[7] M. A. H. Azman, J. M. Aris, Z. Hussain, A. A. A. Samat, and A. M. Nazelan, "A Comparative Study of Fuzzy Logic Controller and Artificial Neural Network in Speed Control of Separately Excited DC Motor," 2017 7th IEEE International Conference on Control System, Computing and Engineering (ICCSCE), Penang, Malaysia, 2017, pp. 336-341, doi: 10.1109/ICCSCE.2017.8284430.

[8] V. R. Rajan, K. Selvi, and L. J. Bery, "Fuzzy Logic Controller Based Dynamic Performance Analysis of AC Drive with SVPWM," 2017 International Conference on Innovations in Information, Embedded and Communication Systems (ICIIECS), Coimbatore, 2017, pp. 1-8, doi: 10.1109/ICIIECS.2017.8276152.

[9] B. Ananthababu, C. Ganesh, C. V. Pavithra, "Fuzzy Based Speed Control of BLDC Motor With Bidirectional DCDC Converter," 2016 Online International Conference on Green Engineering and Technologies (IC-GET), Coimbatore, India, 2016, pp. 1-6, doi: 10.1109/GET.2016.7916647. 
[10] A. Jaya, E. Purwanto, M. B. Fauziah, F. D. Murdianto, G. Prabowo, and M. R. Rusli, "Design of PID-Fuzzy for Speed Control of Brushless DC Motor in Dynamic Electric Vehicle to ImproveSteady-State Performance," 2017 International Electronics Symposium on Engineering Technology and Applications (IES-ETA), Surabaya, Indonesia, 2017, pp. 179-184, doi: 10.1109/ELECSYM.2017.8240399.

[11] N. Pati, and N. Swain, "Design And Study of Speed Control of DC Motor Using Youla Parameterization And PID Controller," 2017 IEEE Calcutta Conference (CALCON), Kolkata, India, 2017, pp. 433-437, doi: 10.1109/CALCON.2017.8280770.

[12] H. T. Rishag, and S. M. Hameed, "Improvement The Dfig Active Power With Variable Speed Wind Using Particle Swarm Optimization," Diyala Journal of Engineering Sciences, vol. 9, no. 2, pp. 12-22, 2016, doi: $10.24237 /$ djes.2016.09205.

[13] H. A. Hasan, and S. M. Hameed, "Characteristics of Earth Electrodes under High Frequency Conditions: Numerical Modelling," 3rd International Conference on Engineering Sciences, IOP Conference Series: Materials Science and Engineering, vol. 671, 2020, doi: 10.1088/1757-899X/671/1/012043.

[14] H. K. I. AL-Qaysi, and S. M. Hameed, "Enhancing the Gain and Power of Folded-cascode Amplifier using Artificial Neural Network," International Journal of Engineering Research and Technology, vol. 12, no. 7, pp. 1117-1125, 2019.

[15] A. S. Kaittan, "Analysis and evaluation of power quality issues in computer-based generation system using custom power devices," International Journal of Civil Engineering and Technology (IJCIET), vol. 10, no. 4, pp. 1870-1879, 2019.

[16] H. G. Abood, G. A. Salman, and A. S. Kaittan, "A Regularized Approach for Solving III Conditioned State Estimation of Distribution Systems," Elektrotehniski Vestnik, vol. 86, no. 3, pp. 137-143, 2019.

[17] H. K. AL-Qaysi, M. M. Jasim, and S. M. Hameed, "Design of very low-voltages and high-performance CMOS gate-driven operational amplifier," Indonesian Journal of Electrical Engineering and Computer Science (IJEECS), vol. 20, no. 2, pp. 670-679, 2020, doi: 10.11591/ijeecs.v20.i2.pp670-679.

[18] M. H. Ali, and Q. Al Azze, "Design and implementation a security system for bank using voice recognition," International Journal of Power Electronics and Drive Systems (IJPEDS), vol. 10, no. 4, pp. 2126-2129, 2019, doi: 10.11591/ijpeds.v10.i4.pp2126-2129.

[19] M. H. Ali, and N. K. Ali, "IoT based security system and intelligent home automation multi monitoring and control systems," IAES International Journal of Robotics and Automation (IJRA), vol. 8, no. 3, pp. 205-210, 2019, doi: 10.11591/ijra.v8i3.pp205-210.

[20] A. S. Kaittan, "Comparison study between solid and litz wires of induction cooker," 2018 1st International Scientific Conference of Engineering Sciences-3rd Scientific Conference of Engineering Science (ISCES), Diyala, Iraq, 2018, pp. 86-91, doi: 10.1109/ISCES.2018.8340533.

[21] A. S. Kaittan, S. M. Hameed, N. K. Ali, and M. H. Ali, "Smart management system for monitoring and control of infant baby bed," International Journal of Electrical and Computer Engineering (IJECE), vol. 10, no. 5, pp. 5025-5031, 2020, doi: 10.11591/ijece.v10i5.pp5025-5031.

[22] R. Y. Abed, A. S. Kaittan, and R. A. Mejeed, "Implementation of a developed water tunnels cleaning model with an automatic sensing and operation mechanism," International Journal of Engineering and Technology, vol. 9, no. 3, pp. 718-723, 2020, doi: 10.14419/ijet.v9i3.30827.

[23] M. A. Abo-Sennah, M. A. El-Dabah, and A. El-Biomey Mansour, "Maximum power point tracking techniques for photovoltaic systems: a comparative study," International Journal of Electrical and Computer Engineering (IJECE), vol. 11, no. 1, pp. 57-73, 2021, doi: 10.11591/ijece.v11i1.pp57-73.

[24] T. T. Nguyen, "Enhanced sunflower optimization for placement distributed generation in distribution system," International Journal of Electrical and Computer Engineering (IJECE), vol. 11, no. 1, pp. 107-113, 2021, doi: 10.11591/ijece.v11i1.pp107-113.

[25] F. Babaa, and O. Bennis, "An accurate inter-turn short circuit faults model dedicated to induction motors," International Journal of Electrical and Computer Engineering (IJECE), vol. 11, no. 1, pp. 9-16, 2021, doi: 10.11591/ijece.v11i1.pp9-16. 